Article

\title{
Affective Instability, Depression, and Anxiety Symptoms in a Community Sample of Pregnant and Postpartum Women: A Cross-Sectional Study
}

\author{
Hua Li (D)
}

check for

updates

Citation: Li, H. Affective Instability, Depression, and Anxiety Symptoms in a Community Sample of Pregnant and Postpartum Women: A CrossSectional Study. Int. J. Environ. Res. Public Health 2022, 19, 3171. https:// doi.org/10.3390/ijerph19063171

Academic Editors: Nicole L. Letourneau and Panagiota Tryphonopoulos

Received: 8 October 2021 Accepted: 24 February 2022 Published: 8 March 2022

Publisher's Note: MDPI stays neutral with regard to jurisdictional claims in published maps and institutional affiliations.

Copyright: (C) 2022 by the author. Licensee MDPI, Basel, Switzerland. This article is an open access article distributed under the terms and conditions of the Creative Commons Attribution (CC BY) license (https:// creativecommons.org/licenses/by/ $4.0 /)$.
College of Nursing, University of Saskatchewan, Health Sciences Building, E-Wing, Room 4248, 104 Clinic Place, Saskatoon, SK S7N 2Z4, Canada; hua.li@usask.ca; Tel.: +1-(306)-966-2158; Fax: +1-(306) 966-6621

\begin{abstract}
Background: Although perinatal women experience an elevated level of affective instability (AI), limited research has been conducted to examine perinatal AI and its relation to depression and anxiety. The current study investigated correlations between AI and depression, between AI and anxiety during the perinatal period, and between current depression and anxiety and the latent factors of the Affective Lability Scale-18 (ALS-18). Methods: 202 Canadian perinatal women participated in this cross-sectional study. The ALS-18 was used to assess AI, while the Depression, Anxiety, and Stress Scale-21 measured depression, anxiety, and stress. Multiple logistic regression was performed to investigate the relationship between $\mathrm{AI}$ and depression and anxiety, and multiple linear regression was conducted to examine the association between current depression and anxiety and the three latent factors of ALS-18. Results: The findings revealed a significant association between AI and depression and between AI and anxiety. Current depression and anxiety were correlated with ALS-18 factors of depression/anxiety shift and depression/elation shift, while current depression was linked to ALS-18 factor of anger. Conclusions: The study findings have important implications for early detection and intervention of maternal anxiety and depression. In order to improve maternal mental health, AI should be included in routine perinatal check-ups.
\end{abstract}

Keywords: affective instability; depression; anxiety; perinatal women

\section{Introduction}

The transition to motherhood often represents a period where women face increased vulnerability to developing anxiety and mood-related disturbances, including depression and affective instability (AI) [1-3]. These mood-related symptoms and anxiety are thought to be caused by hormonal fluctuations that occur during this period of time $[4,5]$. In the past several decades, depression and anxiety during pregnancy and postpartum have been researched extensively because of their possible adverse effects on mothers and their offspring's physical and mental health [6-9]. For example, during the perinatal period, women who experience depressive and/or anxiety symptoms are more likely to experience somatic symptoms and withdrawal, use substances, experience complications during labor/birth, and less likely to attend perinatal classes and routine check-ups and adhere to a nutritious diet $[6,10-15]$. Studies show that mothers with perinatal depression are at a significantly higher risk for suicidality $[7,16]$. In addition, antenatal depression and anxiety have been associated with adverse neonatal outcomes such as low BW, small for gestational age (SGA), preterm birth, and low Apgar score [17-20]. Significant associations between postpartum depression and internalizing and externalizing psychopathologies in children have been documented in a meta-analysis study [21], while antenatal depression has been linked with an increase in child externalizing difficulties and a decrease in cognitive function [22]. Antenatal anxiety is positively linked with behavior and emotional problems in children [23], and postpartum anxiety has negative effects on children's temperament, 
sleep, and cognitive development [24]. However, AI has been largely neglected, even though mood fluctuations are a prominent feature in pregnant and postpartum women [25].

Affective instability is defined as sudden and extreme mood fluctuations in an individual over time [26]. Due to a lack of agreement on the definition, AI is sometimes used interchangeably with mood dysregulation, affective lability, emotional dysregulation, and mood swings [27]. As a transdiagnostic concept in mental health, the prevalence of AI in the adult population is estimated at $13.9 \%$ based on the Psychiatric Morbidity Survey in the UK [28]. Emotional experiences including negative affects and neuroticism have been associated with $\mathrm{AI}$ according to psychological functioning studies $[29,30]$, while the literature supports the notion that $\mathrm{AI}$ is correlated with psychopathologies in the general population and clinical samples including anxiety and depression [31]. AI has also been identified as an independent predictive factor in explaining suicidal thoughts in population studies [32,33].

Affective instability has been known as a part of women's life during their reproductive years, especially during pregnancy and postpartum [34,35]. Based on the literature $[8,36,37]$, $\mathrm{AI}$ in perinatal women has been investigated largely under the concept of postpartum blues, a time frame of 14 days after giving birth, while AI as a distinct feature across pregnancy and postpartum period has been less studied. In a longitudinal study, Bowen A. et al. [25] found that perinatal women experience a significantly higher level of AI at early and late pregnancy and postpartum compared to non-perinatal women with normal menstrual cycles. A recent study investigated the relationship between AI and depression and showed that perinatal AI was strongly correlated with depression at early and late pregnancy and postpartum cross-sectionally, while AI at early pregnancy was significantly associated with postpartum depression prospectively while controlling baseline depression [38], which is in agreement with previous studies in non-perinatal women populations $[39,40]$. Although previous evidence suggests that $\mathrm{AI}$ is linked to depression among perinatal women, few studies have been conducted, especially using validated instruments to measure AI, such as Affective Lability Scale-18 [41], Affective Control Scale [42].

The current study aimed to investigate the associations between AI and depression and between $\mathrm{AI}$ and anxiety after adjusting for other confounders in a community sample of pregnant and postpartum women.

\section{Materials and Methods}

\subsection{Participants and Procedure}

A total of 202 pregnant and postpartum women participated in this cross-sectional study, and they came from nine different provinces in Canada through an online survey from April 2020 to October 2020. Advertisement of recruitment information was posted on several reputable Canadian maternal websites (e.g., This West Coast Mommy, Ooh! Motherhood). Inclusion criteria included Canadian women who were English-speaking, $\geq 18$ years old, and pregnant or within 12 months of postpartum. Ethics approval was obtained from the Behavioural Research Ethics Board of the University of Saskatchewan. Online informed consent was obtained from all participants. All participating women received an honorarium of 10 Canadian dollar e-gift card.

\subsection{Measures}

Affective instability. AI was measured by using the Affective Lability Scale-18, an 18-item self-reported questionnaire [41]. The respondents rated their AI symptoms on a 4-point (0-3) scale ranging from "very uncharacteristic of me" to "very characteristic of me" with a maximum score of 54. Factor analysis studies on three latent factors of the ALS-18 suggested a good fit: anxiety/depression shift (items 1, 3, 5, 6, and 7), depression/elation shift (items 2, 10,12,13,15,16,17, and 18), and anger (items 4, 8, 9, 11, and 14) [41]. Psychometric properties of ALS-18 have been examined in different populations, including in patients with personality disorders, ADHD, bipolar disorder, and in perinatal women with mood symptoms, and the studies recommended the ALS-18 as a valid instrument for 
assessing AI [43-46]. The cutoff score for AI symptoms was based on the mean of ALS-18 (>mean vs. $\leq$ mean).

Depression, anxiety, and stress. The Depression, Anxiety, and Stress Scale -21 (DASS21) was used to assess depression, anxiety, and stress among participating women [47]. This 21-item self-report questionnaire includes three subscales: depression (items 3, 5, 10, 13, 16, 17, and 21), anxiety (items 2, 4 7, 9, 15, 19, and 20) and stress (items 1, 6, 8, 11, 12, 14 , and 18) [47]. The respondents rated each item in the past week ranging from 0 (did not apply to me at all) to 3 (applied to me very much). To be compatible with the DASS-42 cut-offs, the DASS-21 score needs to be multiplied by 2 [47]. Cutoff scores for clinically significant symptoms are suggested to be 60 for the total score, while cutoff scores for subscales of depression, anxiety, and stress to be 21, 15, and 26, respectively [48].

As a measure of three distinct constructs, DASS-21 was an appropriate instrument for the current study for the following reasons. First, the psychometric properties of the instrument are well-established in assessing depression, anxiety, and stress in clinical and nonclinical populations [47,49-51], including perinatal women [52,53]. A high level of internal consistency (Cronbach's $\alpha$ ) was found for all subscales: 0.84 for depression, 0.77 for anxiety, and 0.86 for stress in postpartum women [54]. In terms of DASS-21 total, internal consistency of 0.74 in pregnancy and 0.79 in postpartum was reported [55].

Secondly, with regard to convergent validity, the DASS-21 depression subscale is highly positively correlated with EPDS $(r=0.84)$ and with Beck Depression Inventory (BDI-II, $\mathrm{r}=0.82$ ), while the DASS-21 anxiety subscale is strongly correlated with the Beck Anxiety Inventory $(r=0.86)$ [56]. DASS-21 is frequently used to measure depression and anxiety among perinatal women [55,57-59].

Social support. The multidimensional Scale of Perceived Social Support (MSPSS) was used to measure social support among participating women [60]. MSPSS is a self-reported scale with 12 items that assesses the perceived social support that an individual receives from three sources: friends (items 6, 7, 9, and 12), family (items 3, 4, 8, and 11), and significant other (items 1, 2, 5, and 10) [60]. Each item is rated on a seven-point Likert scale with responses ranging from very strongly disagree $(=1)$ to very strongly agree $(=7)$ with a total possible score of 84 . MSPSS show high internal reliability of Cronbach's $\alpha 0.88$ for the total score, and 0.91, 0.87, and 0.85 for the subscales of significant other, family, and friends, respectively [60], while in another study, Cronbach's $\alpha$ for the three subscales were $0.85,0.90$, and 0.88 , respectively, and for the total scale it was 0.87 [61]. MSPSS has been used in assessing social support among perinatal women [62,63]. The cutoff score for social support was based on the mean of MSPPS, and MSPPS subscales of significant other, family, and friends (>mean vs. $\leq$ mean).

Other information of participating women was also collected including sociodemographic variables, history of depression and/or anxiety, family history of mental illness, complications during pregnancy or labor/birth, preterm birth, and baby's overall health.

\subsection{Data Analyses}

\subsubsection{Descriptive Statistics}

Descriptive statistical analysis was conducted to summarize the characteristics of the participants. The percentages of women who scored above the mean of ALS-18, above or equal to the thresholds of depression, anxiety, and stress DASS-21 subscales, and above the mean of MSPPS were calculated. Group-specific descriptive statistical analyses were also performed to describe AI levels in all women and pregnant and postpartum women. Cronbach's $\alpha$ was calculated to assess internal reliability for all measures.

\subsubsection{Group Comparisons}

Two-sample t-test was used to compare the mean of AI between women with $\geq 21$ on the DASS-21 depression subscale and women with $<21$ on the DASS-21 depression subscale, between women with $\geq 15$ on the DASS-21 anxiety subscale and women with $<15$ on the DASS-21 anxiety subscale, between women with $\geq 26$ on the DASS-21 stress 
subscale and women with $<26$ on the DASS-21 stress subscale, and between women who scored higher than the mean on MSPPS and women who scored below or equal to the mean on MSPPS.

\subsubsection{The Correlation of Perinatal AI with Depression and Anxiety}

To investigate the association between AI and depression and between AI and anxiety, binary logistic regression analysis was used to generate univariate odds ratios associated with each independent variable, including depression, anxiety, sociodemographic variables (marital status, ethnicity, educational attainment, family financial situation), history of depression, history of anxiety, family history of mental illness, stress, social support, complications during pregnancy or labor/birth, preterm birth, and baby's overall health. Multiple logistic regression was employed for variables with $p \leq 0.25$ in univariate analyses.

The ALS-18 is rested on three dimensions: anxiety/depression shift, depression/elation shift, and anger [41]. We conducted linear regression analysis to examine the relationship between each dimension of ALS-18 and current depression or anxiety.

The results were considered to provide evidence of significance if $p$-values $<0.05$ ( $\alpha$ level of $5 \%$ ). The data were analyzed using SPSS 27.

\section{Results}

\subsection{Characteristics of Participating Women}

A total of 202 perinatal women participated in the study, including 94 pregnant women with a mean of 23.6 weeks of pregnancy $(S E=10.04)$ and 108 postpartum women with a mean of 24.4 weeks of postpartum $(S E=15.03)$. Table 1 presents the characteristics of the participating women.

Table 1. Characteristics of participating women $(n=202)$.

\begin{tabular}{cc}
\hline Variables & $N$ (\%) \\
\hline Maternal status & $94(46.5)$ \\
\hline Pregnant & $18(19.2)$ \\
\hline First trimester & $33(35.1)$ \\
\hline Second trimester & $43(45.7)$ \\
\hline Third trimester & $108(53.5)$ \\
\hline Postpartum & $9(8.3)$ \\
\hline 4 weeks & $56(51.9)$ \\
\hline Week 5-6 months & $43(39.8)$ \\
\hline $7-12$ months & $192(95.0)$ \\
\hline Live with partner & $8(4.0)$ \\
\hline Yes & $2(1.0)$ \\
\hline No & $17(8.4)$ \\
\hline Missing & $57(28.2)$ \\
\hline Educational Level & $128(63.4)$ \\
\hline High school & $7(3.5)$ \\
\hline Post-secondary & \\
\hline University & \\
\hline Not good & \\
\hline
\end{tabular}


Table 1. Cont.

\begin{tabular}{cc}
\hline Variables & $N(\mathbf{\%})$ \\
\hline Average & $108(53.4)$ \\
\hline Good & $86(42.6)$ \\
\hline Missing & $1(0.5)$ \\
\hline Ethnicity & $166(79.2)$ \\
\hline Caucasian & $19(9.4)$ \\
\hline Asian & $7(3.5)$ \\
\hline Indigenous & $7(3.5)$ \\
\hline Hispanic/Latino & $9(4.4)$ \\
\hline Not specified &
\end{tabular}

\subsection{Psychosocial Characteristics of Participating Women and Group Comparisons}

Affective instability was common, present in 50\% of the participating women (ALS-18 score $>$ mean), while $24.3 \%$ of women were screened positive for depression (DASS-21 depression subscale score $\geq 21$ ), $28.7 \%$ had a score for anxiety above the threshold (DASS-21 anxiety subscale score $\geq 15$ ), 37.1\% felt stressed (DASS-21 stress subscale score $\geq 26$ ), and $38.1 \%$ reported a lack of social support ( $\leq$ mean of MSPSS score) (Table 2 ).

Table 2. Mean scores of ALS-18, DASS-21 (total and subscales), MSPSS (total and subscales), and results of Cronbach's $\alpha$ in all participating women $(n=202)$.

\begin{tabular}{ccccc}
\hline Measurements & Mean & SD & $\begin{array}{c}\text { Scores } \geq \\
\text { Cut-Off (\%) }\end{array}$ & Cronbach's $\alpha$ \\
\hline ALS-18 score & 19.82 & 11.28 & & 0.926 \\
\hline ALS-18 Total $>$ mean & 29.07 & 6.76 & 50.00 & \\
ALS-18 Total $\leq$ mean & 10.56 & 6.09 & & \\
DASS-21 Total $\geq 60$ & 35.00 & 8.11 & \\
DASS-21 Total $<60$ & 18.42 & 10.49 & \\
DASS-21 Depression Subscale $\geq 21$ & 29.04 & 8.60 & \\
DASS-21 Depression Subscale $<21$ & 16.86 & 10.42 & \\
DASS-21 Anxiety Subscale $\geq 15$ & 27.66 & 9.40 & \\
DASS-21 Anxiety Subscale $\geq 15$ & 16.66 & 10.43 & & \\
DASS-21 Stress Subscale $\geq 26$ & 27.83 & 9.09 & & \\
DASS-21 Stress Subscale $\geq 26$ & 15.09 & 9.68 & & \\
MSPS Total $>$ mean & 25.92 & 9.57 & & \\
MSPSS Total $\leq$ mean & 16.06 & 10.61 & & \\
DASS-21 score & 26.35 & 19.65 & & \\
DASS-21 Total $\geq 60$ & 70.82 & 12.67 & \multirow{2}{*}{8.42} & \\
DASS-21 Total $<60$ & 22.26 & 14.43 & & \\
DASS-21 Depression Subscale score & 16.51 & 16.39 & & \\
DASS-21 Depression Subscale $\geq 21$ & 41.31 & 13.52 & 24.25 & \\
DASS-21 Depression Subscale $<21$ & 8.58 & 6.01 & & \\
DASS-21 Anxiety Subscale score & 11.41 & 13.70 & & \\
DASS-21 Anxiety Subscale $\geq 15$ & 29.10 & 13.10 & 28.71 & \\
DASS-21 Anxiety Subscale $\geq 15$ & 4.28 & 4.14 & & \\
DASS-21 Stress Subscale score & 23.47 & 16.75 & \multirow{2}{*}{37.13} & \\
DASS-21 Stress Subscale $\geq 26$ & 40.16 & 10.99 & \\
DASS-21 Stress Subscale $\geq 26$ & 13.61 & 7.81 & & \\
\hline
\end{tabular}


Table 2. Cont.

\begin{tabular}{ccccc}
\hline Measurements & Mean & SD & $\begin{array}{c}\text { Scores } \geq \\
\text { Cut-Off (\%) }\end{array}$ & Cronbach's $\boldsymbol{\alpha}$ \\
\hline MSPSS total score & 68.01 & 12.87 & & 0.936 \\
MSPSS score $\leq$ mean & 55.21 & 11.10 & 38.12 & \\
MSPSS score $>$ mean & 75.90 & 5.33 & & 0.903 \\
MSPSS significant other subscale score & 24.09 & 4.50 & & \\
Subscale score $\leq$ mean & 20.26 & 4.41 & 43.10 & \multirow{2}{*}{0.912} \\
Subscale score $>$ mean & 27.00 & 1.18 & & \\
MSPSS family subscale score & 22.52 & 5.13 & & \\
Subscale score $\leq$ mean & 18.61 & 4.66 & 48.51 & \\
Subscale score $>$ mean & 26.20 & 1.64 & & \\
MSPSS friends subscale score & 21.40 & 5.32 & & \\
Subscale score $\leq$ mean & 17.52 & 4.48 & 48.02 & \\
Subscale score $>$ mean & 25.56 & 1.85 & & \\
\hline
\end{tabular}

The means and standard deviations of ALS-18 score, DASS-21 total and subscales scores, MSPSS total and subscales scores, and percentage of women who scored above or equal to the threshold of all measures are presented in Table 2. The results of Cronbach's $\alpha$ (ranging from 0.805 to 0.936 ) indicated high internal consistency for all measures (Table 2).

When comparing groups of women who scored above or equal to the threshold of each measure and who scored below the threshold of each measure (AI, depression, anxiety, or stress), the results of two-sample t-test statistics with the degree of freedom showed that women who scored above or equal to the threshold of each measure experienced a significantly higher level of AI (ALS-18 score: $\mathrm{t}(197)=20.44, p<0.001)$, a higher level of depression (DASS-21 depression subscale: $\mathrm{t}(54)=16.43, p<0.001$ ), a higher level of anxiety (DASS-21 anxiety subscale: $\mathrm{t}(62)=14.15, p<0.001$ ), and a higher level of stress (DASS-21 stress subscale: $\mathfrak{t}(119)=18.36, p<0.001$ ). Women who reported a lack of social support showed a significantly elevated level of AI in comparison with that of their counterparts (MSPSS: $\mathbf{t}(98)=15.30, p<0.001)$.

For the level of AI in different group comparisons, the AI level in women who scored above or equal to the threshold of each measure and those who scored below the threshold of each measure (depression, anxiety, stress, or lack of social support) displayed significant group differences (depression: $\mathrm{t}(97)=8.17, p<0.001$; anxiety: $\mathrm{t}(116)=7.29, p<0.001$; stress: $\mathrm{t}(163)=9.390, p<0.001$; social support: $\mathrm{t}(174)=6.82, p<0.001$, respectively). Means on each item of ALS-18 among all participating women, women with depression symptoms, and women with anxiety symptoms are presented in Figure 1.

When comparing pregnant and postpartum women, there were no significant group differences in AI $(t(197)=0.11, p=0.913)$, depression $(t(193)=0.579, p=0.564)$, anxiety $(\mathrm{t}(164)=1.78, p=0.077)$, stress $(\mathrm{t}(194)=0.087, p=0.931)$, and social support $(\mathrm{t}(200)=0.82$, $p=0.412)$.

\subsection{The Association between AI and Depression and Anxiety}

A majority of independent variables showed a statistically significant correlation with AI in univariate logistic regression (Supplement Table S1). Multivariate logistic regression results revealed that depression, anxiety, history of depression, history of anxiety, and support from significant others were strongly linked to AI (Table 3), indicating significant independent effects, while holding all other variables constant. Estimated ORs from the model indicated that women with scores above or equal to the threshold for depression and anxiety were 3.87 times and 2.97 times more likely to experience AI symptoms, respectively (Table 3). Even though stress and social support from family and friends were found to be significantly associated with AI in univariate analysis, they were not established as independently operating risk factors in multivariate logistic regression analysis. 


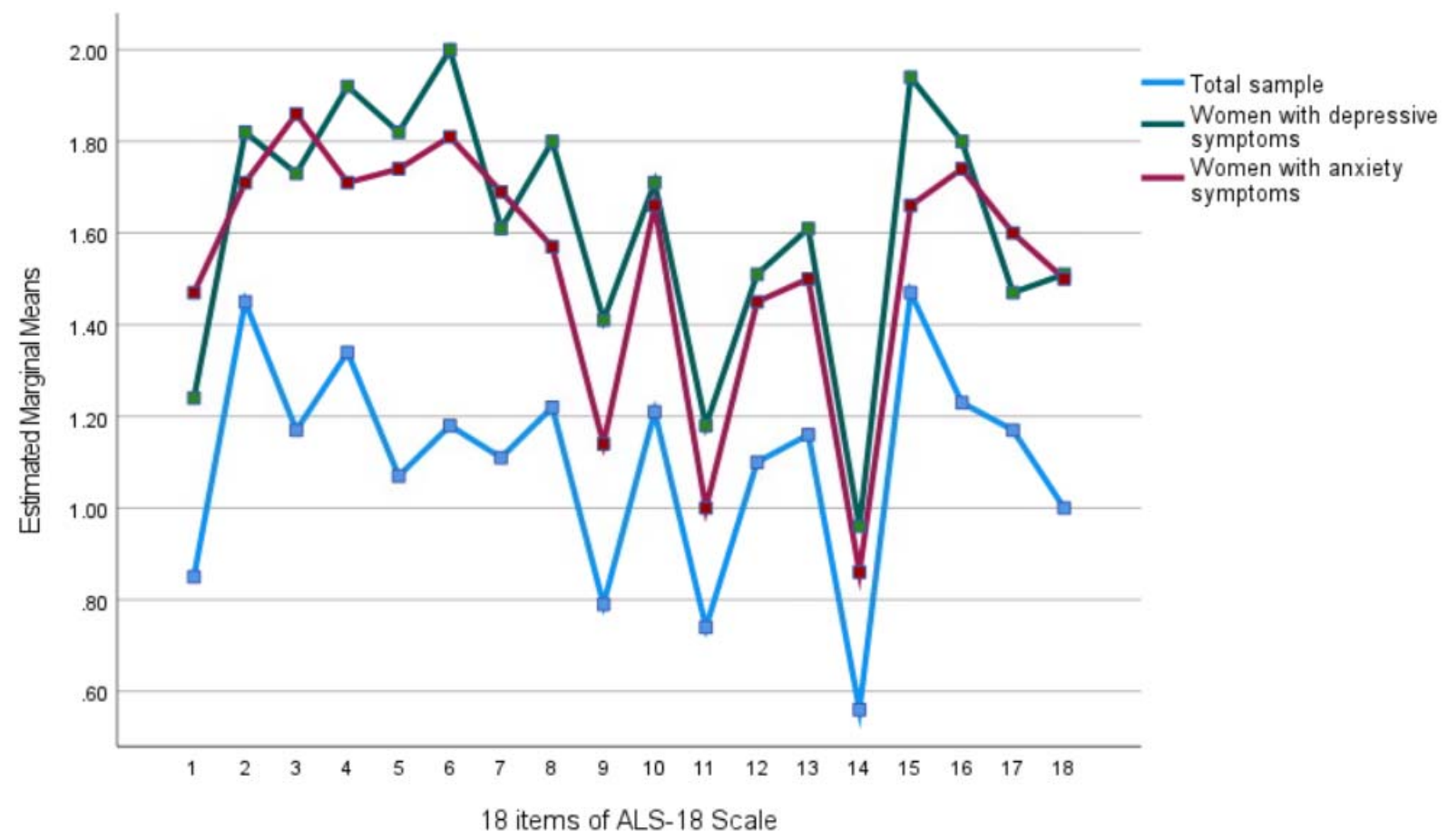

Figure 1. The cross-sectional association of perinatal affective instability, depression, and anxiety.

History of depression and history of anxiety were strongly associated with current AI. To assess whether the associations were due to including women who experienced depression and/or anxiety currently, we examined the associations by excluding women with current depression and/or anxiety, respectively, and the results showed that history of depression and history of anxiety were still significantly linked with current AI $(\mathrm{t}(151)=3.57, p=0.001 ; \mathrm{t}(142)=3.44, p<0.001$ respectively $)$.

Table 3. Multiple logistic regression results of associations between AI and depression, anxiety, and other variables $(n=202)$.

\begin{tabular}{ccc}
\hline Variables & Odds Ratio $(\mathbf{9 5} \% \mathbf{C I})$ & $p$-Value \\
\hline Depression & $3.874(1.340-11.202)$ & 0.012 \\
\hline Anxiety & $2.973(1.259-7.019)$ & 0.013 \\
\hline History of depression & $0.419(0.186-0.942)$ & 0.035 \\
\hline History of anxiety & $0.275(0.111-0.683)$ & 0.005 \\
\hline Support from significant other & $0.304(0.142-0.651)$ & 0.002 \\
\hline
\end{tabular}

Current depression and anxiety were significantly associated with the ALS-18 factor of depression/anxiety (affect shift between depression and anxiety, estimate coefficient for depression and anxiety: 2.315 and 3.454, respectively) and with the ALS-18 factor depression/elation (affect shift between depression and elation, estimate coefficient for depression and anxiety: 3.392 and 2.777, respectively), while depression was linked to the ALS-18 factor of anger (estimate coefficient for depression: 2.979) (Table 4). 
Table 4. Linear regression results of associations between three dimensions of ALS-18 and depression and anxiety $(n=202)$

\begin{tabular}{ccc}
\hline Variables & Estimate Coefficient (95\% CI) & $p$-Value \\
\hline & ALS-18 factor: depression/anxiety shift & $<0.001$ \\
\hline Depression & $2.315(1.139-3.490)$ & $<0.001$ \\
\hline Anxiety & $3.454(2.342-4.567)$ & $<0.001$ \\
\hline Depression & ALS-18 factor: depression/elation shift & 0.002 \\
\hline Anxiety & $3.392(1.515-5.269)$ & $<0.001$ \\
\hline & $2.777(0.999-4.555)$ & 0.091 \\
\hline Depression & ALS-18 factor: anger & \\
\hline Anxiety & $2.979(1.756-4.203)$ & \\
\hline
\end{tabular}

\section{Discussion}

The first main finding of this study was that perinatal AI was strongly and independently associated with depression and anxiety. Our findings replicate those of previous work in general and clinical populations [40,64] and confirm the relationship between AI and depression in perinatal women [38] while filling the research gap of associations between $\mathrm{AI}$ and anxiety and between a history of anxiety and $\mathrm{AI}$ in pregnant and postpartum women. It is the first known study using a validated instrument to examine AI in perinatal women and its relations to depression and anxiety.

Previous research found that history of depression or history of anxiety are identified as the strongest predictors for current depression or anxiety, respectively, in both perinatal and non-perinatal populations [65-67]. Studies elucidating the correlations largely under the stress causation theory suggest that even after a depressive or anxiety episode, a heightened level of stress, including interpersonal stress and non-interpersonal chronic life stress, continues to be maintained for a period of time in individuals with depressive and/or anxiety disorders $[68,69]$, while neuroticism as a shared property between depression, anxiety, and AI, partially accounts for the associations [69]. In the current study, a history of depression or a history of anxiety was linked to current AI while excluding women with current depression or anxiety, indicating that a history of depression or a history of anxiety independently predict current AI, which may be explained by the stress causation theory.

Notably, current depression and anxiety were significantly associated with ALS-18 factors of depression/anxiety shift and depression/elation shift. The associations may be elucidated by the high comorbidity between depression and anxiety [70], hypomania as a core symptom of depression [71], and strong genetic correlations between AI, depression, and anxiety [72]. The findings are also in agreement with those of a previous study that suggested that affective experiences in perinatal women can be depicted in a labile fashion [43]. Additionally, depression was linked with the ALS-18 factor of anger in this study, which confirmed the notion that anger is a prominent feature of depression and plays an integral role in the development of depression [73].

As a transdiagnostic concept, $\mathrm{AI}$ and its relationship with depression and anxiety have been illustrated as sharing some correlates, including neuroticism, negative affect, stress, and emotional awareness [74,75]. Furthermore, there is evidence of a genetic association between AI, depression, and anxiety [72]. Neuroticism, negative affect, and stress as shared properties among AI, depression, and anxiety have been discussed in a previous study [76]. Empirical research implicated the relationship between emotional awareness, emotion regulation, and psychopathologies including depression and anxiety by elucidating that emotional awareness (i.e., attending to and understanding one's own emotion) is essential for effective emotion regulation [77], while emotional awareness has been consistently recognized as a strong predictor for an array of psychopathologies via associations with 
emotion dysregulation [78]. Studies have further explained the relationship by suggesting that emotional awareness is associated with the implementation of emotion regulation strategies $[79,80]$. For example, an individual who understands his/her emotion clearly is more likely to effectively utilize emotion regulation strategies including cognitive reappraisal, expressive suppression, and nonjudgmental acceptance of emotion [80]. Thus, emotional awareness and emotion regulation together contribute to psychopathology including depression and anxiety. For genetic evidence, researchers in the UK conducted a genome-wide study of mood instability in 53,525 cases and 60,443 controls from Biobank and found a significant genetic correlation between mood instability, depression, anxiety, and schizophrenia [72].

Lack of social support from significant others was identified as a risk factor for AI in this study. During the perinatal period, women experience tremendous changes physically and psychologically which require major adjustments, and social support plays a crucial role to help women cope with the transition to motherhood [81,82]. Lack of social support from partners, family, and/or friends can be reflected in a lack of social stability and social participation, which has a negative impact on the psychological wellbeing of perinatal women, including experiencing stress $[83,84]$. While there is limited study on the correlation between $\mathrm{AI}$ and social support, the significant link found in this study may be explained by the evidence of the relationship between $\mathrm{AI}$ and stress in previous research. For example, a bidirectional relationship between AI and stress has been suggested [85]. Mood fluctuations may be the result of life stresses, while frequent mood shifts may cause stressful events to occur (e.g., job loss, interpersonal relationship difficulties).

There are some implications from this study. Given the evidence of the strong association between $\mathrm{AI}$ and depression and between AI and anxiety in perinatal women, expanding the view of perinatal mood symptoms could help understand perinatal women's affective experience in a more comprehensive way, particularly for healthcare providers who most likely pay attention to diagnosable entities such as depression and anxiety when evaluating mood and anxiety symptoms in perinatal women. From early detection and early intervention perspectives, perinatal routine check-ups should include AI assessment that would provide another opportunity to identify women who are at risk for developing depression and/or anxiety, including women who have a history of depression and/or anxiety. In addition, the strong association between social support and perinatal depression and anxiety has been well-established [86], while the new evidence in our study revealed the significant relationship between social support and AI in perinatal women. Thus, our finding further supports the recommendation that social support should be a targeted risk factor for preventing the development of mood and anxiety symptoms or alleviating the symptoms during the perinatal period. Furthermore, interpersonal violence during the perinatal period and its negative impact on maternal mental health have been documented [87]. However, there are very limited studies on the topic of the association between interpersonal violence and AI in pregnant and postpartum women. Future research is required to explore the relation of perinatal AI with interpersonal violence.

There are several limitations in this study, including possible misrepresentations of online recruitment methods, and the composition of participants (e.g., predominantly Caucasians among study participants, self-selected sample). As a property of AI, temporality indicates that the experience of AI may change throughout the day, thus a cross-sectional design of the current study may not capture AI experience accurately. A detailed description of the limitation was discussed in a previous publication ( $\mathrm{Li}$ et al., 2021). In addition, the impact of COVID-19 on mental health and psychological wellbeing has been reported [88-90]. The pandemic might have effects on participating women's mood, anxiety, and other emotional experiences, which was not included in the data collection of this present study. Therefore, the findings of this study must be interpreted with caution. 


\section{Conclusions}

The findings of this current study showed strong independent associations between perinatal AI and depression and between perinatal AI and anxiety and revealed that women's affective experiences can be depicted in a labile fashion during the perinatal period. Thus, in order to improve maternal mental health, AI should be included in perinatal affective experiences research and clinical practice. More studies are required in this under-researched area.

Supplementary Materials: The following supporting information can be downloaded at: https: / / www.mdpi.com/article/10.3390/ijerph19063171/s1, Table S1: Univariate logistic regression results of the association between $\mathrm{AI}$ and other variables.

Funding: This work was supported by the CIHR Seed Grant, College of Nursing, the University of Saskatchewan.

Institutional Review Board Statement: The study was conducted in accordance with the Declaration of Helsinki, and approved by the Behavioural Research Ethics Board of the University of Saskatchewan (Beh-REB\# 1540, 14 Feburary 2020).

Informed Consent Statement: Informed consent was obtained from all subjects involved in the study.

Data Availability Statement: All data generated or analyzed during this study are included in this article including supplement table. Further enquiries can be directed to the corresponding author.

Acknowledgments: The authors would like to thank the women who participated in this study and Alana Glecia for assisting recruitment and data collection.

Conflicts of Interest: The authors declare no conflict of interests.

\section{References}

1. Buist, A.E.; Austin, M.-P.V.; Hayes, B.A.; Speelman, C.; Bilszta, J.; Gemmill, A.W.; Brooks, J.; Ellwood, D.; Milgrom, J. Postnatal Mental Health of Women Giving Birth in Australia 2002-2004: Findings from the Beyondblue National Postnatal Depression Program. Aust. N. Z. J. Psychiatry 2008, 42, 66-73. [CrossRef] [PubMed]

2. Milgrom, J.; Gemmill, A.W. Screening for perinatal depression. Best Pract. Res. Clin. Obstet. Gynaecol. 2014, 28, 13-23. [CrossRef] [PubMed]

3. Sharma, V.; Sharma, P. Postpartum Depression: Diagnostic and Treatment Issues. J. Obstet. Gynaecol. Can. 2012, 34, 436-442. [CrossRef]

4. Buttner, M.M.; O'Hara, M.W.; Watson, D. The Structure of Women's Mood in the Early Postpartum. Assessment 2011, 19, 247-256. [CrossRef]

5. Cunningham, F.; Leveno, K.; Bloom, S.; Hauth, J.; Rouse, D.; Spong, C. Williams Obstetrics, 23rd ed.; McGraw Hill: New York, NY, USA, 2010

6. O'Hara, M.W. Postpartum depression: What we know. J. Clin. Psychol. 2009, 65, 1258-1269. [CrossRef]

7. Sit, D.; Luther, J.; Buysse, D.; Dills, J.L.; Eng, H.; Okun, M.; Wisniewski, S.; Wisner, K. Suicidal ideation in depressed postpartum women: Associations with childhood trauma, sleep disturbance and anxiety. J. Psychiatr. Res. 2015, 66-67, 95-104. [CrossRef]

8. O'Hara, M.W.; McCabe, J.E. Postpartum Depression: Current Status and Future Directions. Annu. Rev. Clin. Psychol. 2013, 9 , 379-407. [CrossRef]

9. Bell, M.F.; Bayliss, D.; Glauert, R.; Harrison, A.; Ohan, J. Children of parents who have been hospitalised with psychiatric disorders are at risk of poor school readiness. Epidemiol. Psychiatr. Sci. 2018, 28, 508-520. [CrossRef]

10. Leigh, B.; Milgrom, J. Risk factors for antenatal depression, postnatal depression and parenting stress. BMC Psychiatry 2008, 8, 24. [CrossRef]

11. Lee, A.M.; Lam, S.K.; Lau, S.M.S.M.; Chong, C.S.Y.; Chui, H.W.; Fong, D.Y.T. Prevalence, Course, and Risk Factors for Antenatal Anxiety and Depression. Obstet. Gynecol. 2007, 110, 1102-1112. [CrossRef]

12. Bonari, L.; Bennett, H.; Einarson, A.; Koren, G. Risks of untreated depression during pregnancy. Can. Fam. Physician 2004, 50, 37-39. [CrossRef] [PubMed]

13. Chan, J.; Natekar, A.; Einarson, A.; Koren, G. Risks of untreated depression in pregnancy. Can. Fam. Physician 2014, 60, 242-243. [PubMed]

14. Andersson, L.; Sundström-Poromaa, I.; Wulff, M.; Åström, M.; Bixo, M. Neonatal outcome following maternal antenatal depression and anxiety: A population-based study. Am. J. Epidemiol. 2004, 159, 872-881. [CrossRef] [PubMed]

15. Wilkie, G.L.; Deligiannidis, K.M. Effects of Perinatal Depression and Anxiety on Labor and Delivery Outcomes. Obstet. Gynecol. 2014, 123, 82S-83S. [CrossRef] 
16. Lindahl, V.; Pearson, J.L.; Colpe, L. Prevalence of suicidality during pregnancy and the postpartum. Arch. Women's Ment. Health 2005, 8, 77-87. [CrossRef] [PubMed]

17. Patel, V.; Prince, M. Maternal psychological morbidity and low birth weight in India. Br. J. Psychiatry 2006, 188, $284-285$. [CrossRef] [PubMed]

18. Li, D.; Liu, L.; Odouli, R. Presence of depressive symptoms during early pregnancy and the risk of preterm delivery: A prospective cohort study. Hum. Reprod. 2008, 24, 146-153. [CrossRef] [PubMed]

19. Berle, J.; Mykletun, A.; Daltveit, A.K.; Rasmussen, S.; Holsten, F.; Dahl, A.A. Neonatal outcomes in offspring of women with anxiety and depression during pregnancy. Arch. Women's Ment. Health 2005, 8, 181-189. [CrossRef] [PubMed]

20. Glover, V.; O'Connor, T.; O'Donnell, K. Prenatal stress and the programming of the HPA axis. Neurosci. Biobehav. Rev. 2010, 35, 17-22. [CrossRef] [PubMed]

21. Cuijpers, P.; Weitz, E.; Karyotaki, E.; Garber, J.; Andersson, G. The effects of psychological treatment of maternal depression on children and parental functioning: A meta-analysis. Eur. Child Adolesc. Psychiatry 2014, 24, 237-245. [CrossRef] [PubMed]

22. Barker, E.D.; Jaffee, S.R.; Uher, R.; Maughan, B. The contribution of prenatal and postnatal maternal anxiety and depression to child maladjustment. Depress. Anxiety 2011, 28, 696-702. [CrossRef] [PubMed]

23. O'Connor, T.G.; Heron, J.; Golding, J.; Glover, V.; The AL SPAC Study Team. Maternal antenatal anxiety and behavioural/emotional problems in children: A test of a programming hypothesis. J. Child Psychol. Psychiatry 2003, 44, 1025-1036. [CrossRef] [PubMed]

24. Field, T. Postnatal anxiety prevalence, predictors and effects on development: A narrative review. Infant Behav. Dev. 2018, 51, 24-32. [CrossRef] [PubMed]

25. Bowen, A.; Bowen, R.; Balbuena, L.; Muhajarine, N. Are Pregnant and Postpartum Women Moodier? Understanding Perinatal Mood Instability. J. Obstet. Gynaecol. Can. 2012, 34, 1038-1042. [CrossRef]

26. Trull, T.J.; Solhan, M.B.; Tragesser, S.L.; Jahng, S.; Wood, P.K.; Piasecki, T.M.; Watson, D. Affective instability: Measuring a core feature of borderline personality disorder with ecological momentary assessment. J. Abnorm. Psychol. 2008, 117, 647-661. [CrossRef] [PubMed]

27. Marwaha, S.; He, Z.; Broomé, M.; Singh, S.P.; Scott, J.; Eyden, J.; Wolke, D. How is affective instability defined and measured? A systematic review. Psychol. Med. 2013, 44, 1793-1808. [CrossRef]

28. Marwaha, S.; Parsons, N.; Flanagan, S.; Broome, M. The prevalence and clinical associations of mood instability in adults living in England: Results from the Adult Psychiatric Morbidity Survey. Psychiatry Res. 2012, 205, 262-268. [CrossRef]

29. Miller, D.J.; Vachon, D.D.; Lynam, D.R. Neuroticism, negative affect, and negative affect instability: Establishing convergent and discriminant validity using ecological momentary assessment. Pers. Individ. Differ. 2009, 47, 873-877. [CrossRef]

30. Miller, J.D.; Pilkonis, P.A. Neuroticism and affective instability: The same or different? Am. J. Psychiatry 2006, 163, 839-845. [CrossRef]

31. Broome, M.R.; He, Z.; Iftikhar, M.; Eyden, J.; Marwaha, S. Neurobiological and behavioural studies of affective instability in clinical populations: A systematic review. Neurosci. Biobehav. Rev. 2015, 51, 243-254. [CrossRef]

32. Marwaha, S.; Parsons, N.; Broome, M. Mood instability, mental illness and suicidal ideas: Results from a household survey. Soc. Psychiatry 2013, 48, 1431-1437. [CrossRef] [PubMed]

33. Bowen, R.; Balbuena, L.; Peters, E.M.; Leuschen-Mewis, C.; Baetz, M. The Relationship between Mood Instability and Suicidal Thoughts. Arch. Suicide Res. 2014, 19, 161-171. [CrossRef] [PubMed]

34. Toffol, E.; Heikinheimo, O.; Partonen, T. Hormone therapy and mood in perimenopausal and postmenopausal women: A narrative review. Menopause 2015, 22, 564-578. [CrossRef]

35. Mitchell, C. Mood Swings: The Mindful Way: Managing Anger, Anxiety and Low Mood; Sheldon Press: London, UK, 2017.

36. Li, H.; Bowen, A.; Bowen, R.; Balbuena, L.; Feng, C.; Bally, J.; Muhajarine, N. Mood instability during pregnancy and postpartum: A systematic review. Arch. Women's Ment. Health 2019, 23, 29-41. [CrossRef] [PubMed]

37. Jung, M.-H.; Kim, J.I. A Study on the Relationship among Prenatal Emotional Status, Preparation for Delivery, Postpartum Social Support and Postpartum Blues. Korean J. Women Health Nurs. 2005, 11, 38-45. [CrossRef]

38. Li, H.; Bowen, A.; Bowen, R.; Feng, C.; Muhajarine, N.; Balbuena, L. Mood instability across the perinatal period: A cross-sectional and longitudinal study. J. Affect. Disord. 2019, 264, 15-23. [CrossRef]

39. Marwaha, S.; Balbuena, L.; Winsper, C.; Bowen, R. Mood instability as a precursor to depressive illness: A prospective and mediational analysis. Aust. N. Z. J. Psychiatry 2015, 49, 557-565. [CrossRef]

40. Thompson, R.J.; Berenbaum, H.; Bredemeier, K. Cross-sectional and longitudinal relations between affective instability and depression. J. Affect. Disord. 2011, 130, 53-59. [CrossRef]

41. Oliver, M.N.; Simons, J.S. The affective lability scales: Development of a short-form measure. Pers. Individ. Differ. 2004, 37, 1279-1288. [CrossRef]

42. Williams, K.; Chambless, D.L.; Ahrens, A. Are emotions frightening? An extension of the fear of fear construct. Behav. Res. Ther. 1997, 35, 239-248. [CrossRef]

43. Li, H.; Bowen, A.; Bowen, R.; Balbuena, L.; Baetz, M.; Feng, C.; Muhajarine, N.; Bally, J. Preliminary study: Factor structure and psychometric properties of Affective Lability Scale-18 in pregnant and postpartum women. J. Affect. Disord. 2019, 245, 312-320. [CrossRef] [PubMed] 
44. Aas, M.; Pedersen, G.; Henry, C.; Bjella, T.; Bellivier, F.; Leboyer, M.; Kahn, J.-P.; Cohen, R.F.; Gard, S.; Aminoff, S.R.; et al. Psychometric properties of the Affective Lability Scale (54 and 18-item version) in patients with bipolar disorder, first-degree relatives, and healthy controls. J. Affect. Disord. 2015, 172, 375-380. [CrossRef] [PubMed]

45. Look, A.E.; Flory, J.D.; Harvey, P.D.; Siever, L.J. Psychometric properties of a short form of the Affective Lability Scale (ALS-18). Pers. Individ. Differ. 2010, 49, 187-191. [CrossRef]

46. Weibel, S.; Micoulaud-Franchi, J.-A.; Brandejsky, L.; Lopez, R.; Prada, P.; Nicastro, R.; Ardu, S.; Dayer, A.; Lançon, C.; Perroud, N. Psychometric Properties and Factor Structure of the Short Form of the Affective Lability Scale in Adult Patients with ADHD. J. Atten. Disord. 2017, 23, 1079-1089. [CrossRef] [PubMed]

47. Lovibond, P.F.; Lovibond, S.H. The structure of negative emotional states: Comparison of the Depression Anxiety Stress Scales (DASS) with the Beck Depression and Anxiety Inventories. Behav. Res. Ther. 1995, 33, 335-343. [CrossRef]

48. Lovibond, S.; Lovibond, P. Manual for the Depression Anxiety Stress Scales (DASS); Psychology Foundation of Australia: Sydney, Australia, 1993.

49. Lovibond, S.H.; Lovibond, P.F. Manual for the Depression Anxiety Stress Scales; Psychology Foundation of Australia: Sydney, Australia, 1996.

50. Osman, A.; Wong, J.L.; Bagge, C.L.; Freedenthal, S.; Gutierrez, P.M.; Lozano, G. The depression anxiety stress Scales-21 (DASS-21): Further examination of dimensions, scale reliability, and correlates. J. Clin. Psychol. 2012, 68, 1322-1338. [CrossRef] [PubMed]

51. Cohen, S.; Kamarck, T.; Mermelstein, R. Perceived stress scale. Measuring stress: A guide for health and social scientists. J. Health Soc. Behav. 1994, 24, 386-396.

52. Tran, T.D.; Tran, T.; Fisher, J. Validation of the depression anxiety stress scales (DASS) 21 as a screening instrument for depression and anxiety in a rural community-based cohort of northern Vietnamese women. BMC Psychiatry 2013, 13, 24. [CrossRef]

53. Xavier, S.; Bento, E.; Azevedo, J.; Marques, M.; Soares, M.J.; Freitas, V.; Mota, D.; Macedo, A.; Pereira, A.T. Validation of the Depression, Anxiety and Stress Scale-DASS-21 in a community sample of Portuguese pregnant women. Eur. Psychiatry 2016, 33 , s239. [CrossRef]

54. Miller, R.L.; Pallant, J.F.; Negri, L.M. Anxiety and stress in the postpartum: Is there more to postnatal distress than depression? BMC Psychiatry 2006, 6, 12. [CrossRef]

55. Brassel, A.; Townsend, M.L.; Pickard, J.A.; Grenyer, B.F.S. Maternal perinatal mental health: Associations with bonding, mindfulness, and self-criticism at 18 months' postpartum. Infant Ment. Health J. 2019, 41, 69-81. [CrossRef] [PubMed]

56. Cunningham, N.K.; Brown, P.M.; Brooks, J.; Page, A.C. The structure of emotional symptoms in the postpartum period: Is it unique? J. Affect. Disord. 2013, 151, 686-694. [CrossRef] [PubMed]

57. Yelland, J.; Sutherland, G.; Brown, S.J. Postpartum anxiety, depression and social health: Findings from a population-based survey of Australian women. BMC Public Health 2010, 10, 771. [CrossRef] [PubMed]

58. Rallis, S.; Skouteris, H.; McCabe, M.; Milgrom, J. A prospective examination of depression, anxiety and stress throughout pregnancy. Women Birth 2014, 27, e36-e42. [CrossRef]

59. Prevatt, B.-S.; Desmarais, S.L. Facilitators and Barriers to Disclosure of Postpartum Mood Disorder Symptoms to a Healthcare Provider. Matern. Child Health J. 2017, 22, 120-129. [CrossRef]

60. Zimet, G.D.; Dahlem, N.W.; Zimet, S.G.; Farley, G.K. The multidimensional scale of perceived social support. J. Personal. Assess. 1988, 52, 30-41. [CrossRef]

61. Duru, E. Re-examination of the psychometric characteristics of the multidimensional scale of perceived social support among turkish university students. Soc. Behav. Pers. Int. J. 2007, 35, 443-452. [CrossRef]

62. Hannan, J.; Alce, M.; Astros, A. Psychometric properties of the newly translated creole multidimensional scale of perceived social support (MSPSS) and perceived adequacy of resource scale (PARS) and the relationship between perceived social support and resources in Haitian mothers in the US. BMC Psychol. 2016, 4, 7. [CrossRef]

63. Denis, A.; Callahan, S.; Bouvard, M. Evaluation of the French Version of the Multidimensional Scale of Perceived Social Support During the Postpartum Period. Matern. Child Health J. 2014, 19, 1245-1251. [CrossRef]

64. Bowen, R.; Clark, M.; Baetz, M. Mood swings in patients with anxiety disorders compared with normal controls. J. Affect. Disord. 2004, 78, 185-192. [CrossRef]

65. Guintivano, J.; Manuck, T.; Meltzer-Brody, S. Predictors of Postpartum Depression: A Comprehensive Review of the Last Decade of Evidence. Clin. Obstet. Gynecol. 2018, 61, 591-603. [CrossRef] [PubMed]

66. Dennis, C.-L.; Falah-Hassani, K.; Brown, H.K.; Vigod, S.N. Identifying women at risk for postpartum anxiety: A prospective population-based study. Acta Psychiatr. Scand. 2016, 134, 485-493. [CrossRef] [PubMed]

67. Beekman, A.T.; De Beurs, E.; Van Balkom, A.J.; Deeg, R.J.; Van Dyck, R.; Van Tilburg, W. Anxiety and Depression in Later Life: Co-Occurrence and Communality of Risk Factors. Am. J. Psychiatry 2000, 157, 89-95. [CrossRef] [PubMed]

68. Rudolph, K.D.; Flynn, M.; Abaied, J.L.; Groot, A.; Thompson, R. Why is Past Depression the Best Predictor of Future Depression? Stress Generation as a Mechanism of Depression Continuity in Girls. J. Clin. Child Adolesc. Psychol. 2009, 38, 473-485. [CrossRef]

69. Uliaszek, A.A.; Zinbarg, R.E.; Mineka, S.; Craske, M.G.; Griffith, J.W.; Sutton, J.M.; Epstein, A.; Hammen, C. A longitudinal examination of stress generation in depressive and anxiety disorders. J. Abnorm. Psychol. 2012, 121, 4-15. [CrossRef]

70. Pollack, M.H. Comorbid anxiety and depression. J. Clin. Psychiatry 2005, 66 (Suppl. 8), 22-29. 
71. Balbuena, L.; Bowen, R.; Baetz, M.; Marwaha, S. Mood Instability and Irritability as Core Symptoms of Major Depression: An Exploration Using Rasch Analysis. Front. Psychiatry 2016, 7, 174. [CrossRef]

72. Ward, J.; Strawbridge, R.J.; Bailey, M.E.S.; Graham, N.; Ferguson, A.; Lyall, D.M.; Cullen, B.; Pidgeon, L.M.; Cavanagh, J.; Mackay, D.F.; et al. Genome-wide analysis in UK Biobank identifies four loci associated with mood instability and genetic correlation with major depressive disorder, anxiety disorder and schizophrenia. Transl. Psychiatry 2017, 7, 1264. [CrossRef]

73. Busch, F.N. Anger and depression. Adv. Psychiatr. Treat. 2009, 15, 271-278. [CrossRef]

74. Boden, M.T.; Thompson, R.J. Facets of emotional awareness and associations with emotion regulation and depression. Emotion 2015, 15, 399-410. [CrossRef]

75. Vanhooren, S. Emotional clarity, felt sensing, and existential anxiety: What we can learn from current research and how we can embrace it. In Proceedings of the Loving \& Losing, 3rd Conference of the Federation for Existential Therapy in Europe, London, UK, 25-26 June 2021.

76. Li, H.; Glecia, A.; Balbuena, L. Confirmatory Factor Analysis of the Affective Lability Scale-18 in a Community Sample of Pregnant and Postpartum Women. Women's Reprod. Health 2021, 8, 294-307. [CrossRef]

77. Thompson, R.J.; Boden, M.T.; Gotlib, I.H. Emotional variability and clarity in depression and social anxiety. Cogn. Emot. 2015, 31, 98-108. [CrossRef] [PubMed]

78. Paolacci, G.; Chandler, J. Inside the Turk: Understanding Mechanical Turk as a participant pool. Curr. Dir. Psychol. Sci. 2014, 23, 184-188. [CrossRef]

79. Barrett, L.F.; Gross, J.J. Emotional Intelligence: A Process Model of Emotion Representation and Regulation; Guilford Press: New York, NY, USA, 2001.

80. Gross, J.J. Handbook of Emotion Regulation; Guilford Publications: New York, NY, USA, 2013.

81. Matthey, S. Are we overpathologising motherhood? J. Affect. Disord. 2010, 120, 263-266. [CrossRef] [PubMed]

82. Umberson, D.; Pudrovska, T.; Reczek, C. Parenthood, Childlessness, and Well-Being: A Life Course Perspective. J. Marriage Fam. 2010, 72, 612-629. [CrossRef]

83. Elsenbruch, S.; Benson, S.; Rücke, M.; Rose, M.; Dudenhausen, J.; Pincus-Knackstedt, M.K.; Klapp, B.F.; Arck, P. Social support during pregnancy: Effects on maternal depressive symptoms, smoking and pregnancy outcome. Hum. Reprod. 2006, $22,869-877$. [CrossRef]

84. Giurgescu, C.; Penckofer, S.; Maurer, M.C.; Bryant, F.B. Impact of Uncertainty, Social Support, and Prenatal Coping on the Psychological Well-being of High-risk Pregnant Women. Nurs. Res. 2006, 55, 356-365. [CrossRef]

85. Koenigsberg, H.W.; Harvey, P.D.; Mitropoulou, V.; Schmeidler, J.; New, A.S.; Goodman, M.; Silverman, J.M.; Serby, M.; Schopick, F.; Siever, L.J. Characterizing Affective Instability in Borderline Personality Disorder. Am. J. Psychiatry 2002, 159, 784-788. [CrossRef]

86. Gariépy, G.; Honkaniemi, H.; Quesnel-Vallée, A. Social support and protection from depression: Systematic review of current findings in Western countries. Br. J. Psychiatry 2016, 209, 284-293. [CrossRef]

87. Mazza, M.; Caroppo, E.; Marano, G.; Chieffo, D.; Moccia, L.; Janiri, D.; Rinaldi, L.; Janiri, L.; Sani, G. Caring for Mothers: A Narrative Review on Interpersonal Violence and Peripartum Mental Health. Int. J. Environ. Res. Public Health 2021, $18,5281$. [CrossRef]

88. Kumar, A.; Nayar, K.R. COVID-19 and its mental health consequences. J. Ment. Health 2020, 30, 1-2. [CrossRef] [PubMed]

89. O'Connor, R.C.; Wetherall, K.; Cleare, S.; McClelland, H.; Melson, A.J.; Niedzwiedz, C.L.; O'Carroll, R.E.; O'Connor, D.B.; Platt, S.; Scowcroft, E.; et al. Mental health and well-being during the COVID-19 pandemic: Longitudinal analyses of adults in the UK COVID-19 Mental Health \& Wellbeing study. Br. J. Psychiatry 2021, 218, 326-333. [CrossRef] [PubMed]

90. Hossain, M.; Tasnim, S.; Sultana, A.; Faizah, F.; Mazumder, H.; Zou, L.; McKyer, E.L.J.; Ahmed, H.U.; Ma, P. Epidemiology of mental health problems in COVID-19: A review. F1000Research 2020, 9, 636. [CrossRef] [PubMed] 